\title{
CD8 Treg Cells Inhibit B cell Proliferation and Immunoglobulin Production
}

\author{
Sudhir Gupta ${ }^{1}$, Houfen $\mathrm{Su}^{2}$, and Sudhanshu Agrawal ${ }^{3}$ \\ ${ }^{1}$ University of California \\ ${ }^{2}$ University of California Irvine \\ ${ }^{3}$ University of California, Irvine
}

May 11, 2020

\begin{abstract}
The role of CD4+ Treg in immune responses has been well established. More recently a role of CD8+ Treg in the regulation of immune responses in health and autoimmune diseases has been investigated. Furthermore, different investigators have used different markers to define CD8 Treg. Finally, regulatory effects of CD8 Treg have been studied against T cell responses; however, their role in regulating B cell proliferation and immunoglobulin production has not been evaluated. Therefore, in this study we examined the effect of two types of CD8 Treg on B cell proliferation and immunoglobulin production. Methods: Purified CD8 + T cells were activated with anti-CD3/CD28 for 48 hours and then sorted into two different types of CD8 Treg as defined by two different sets of markers, CD8+CD183+CCR7+CD45RA-, and CD8+CD183+CD25highCD278+. Purified B cells were co-cultured with sorted CD8 Treg at 1:1, 1:1/2, 1:1/4 ratios, and activated with anti-CD40 and CpG. B cell proliferation was assessed by CFSE dye dilution assay and immunoglobulin production by ELISA assay. Results: Our data show CD183+CCR7+CD45RA- CD8 T reg significantly inhibited B cell proliferation and inhibited IgM and IgG production but not of IgA production at 1:1 ratio only. However, CD183+CD25highCD278+ CD8 Treg inhibited significantly B cell proliferation at $1: 1$ and 1:1/2 ratio and $\operatorname{IgM}, \operatorname{IgG}$, and $\operatorname{IgA}$ production at all ratios. In Conclusion, CD8 Treg regulate B cell responses, and CD183+CD25highCD278+ CD8 Treg are more powerful regulators of B cell proliferation and Immunoglobulin production than CD183+CCR7+CD45RA- CD8 Treg.
\end{abstract}

\section{CD8 Treg Cells Inhibit B cell Proliferation and Immunoglobulin Production}

Sudhir Gupta, Houfen Su, Sudhanshu Agrawal

Division of Basic and Clinical Immunology, University of California, Irvine, California, USA

Running title: B cells suppression by CD8 Treg

Correspondence:

Professor Sudhir Gupta

Medical Science I, C-240

University of California at Irvine

Irvine, CA 92697, USA

E-mail: sgupta@uci.edu

Phone: (949) 824-5818

Fax: (949) 824-4362 
Word Count: 2493

Pages 22

\section{SUMMARY}

The role of CD4+ Treg in immune responses has been well established. More recently a role of CD8+ Treg in the regulation of immune responses in health and autoimmune diseases has been investigated. Furthermore, different investigators have used different markers to define CD8 Treg. Finally, regulatory effects of CD8 Treg have been studied against $\mathrm{T}$ cell responses; however, their role in regulating $\mathrm{B}$ cell proliferation and immunoglobulin production has not been evaluated. Therefore, in this study we examined the effect of two types of CD8 Treg on B cell proliferation and immunoglobulin production. Methods: Purified CD8+ T cells were activated with anti-CD3/CD28 for 48 hours and then sorted into two different types of CD8 Treg as defined by two different sets of markers, CD8+CD183+CCR7+CD45RA-, and CD8+CD183+CD25 ${ }^{\text {high }}$ CD278+. Purified B cells were co-cultured with sorted CD8 Treg at 1:1, 1:1/2, 1:1/4 ratios, and activated with anti-CD40 and CpG. B cell proliferation was assessed by CFSE dye dilution assay and immunoglobulin production by ELISA assay.

Results: Our data show CD183+CCR7+CD45RA- CD8 T reg significantly inhibited B cell proliferation and inhibited $\operatorname{IgM}$ and $\operatorname{IgG}$ production but not of $\operatorname{IgA}$ production at 1:1 ratio only. However, CD183+CD25 ${ }^{\text {high }}$ CD278+ CD8 Treg inhibited significantly B cell proliferation at 1:1 and 1:1/2 ratio and $\operatorname{IgM}, \operatorname{IgG}$, and IgA production at all ratios. In

Conclusion, CD8 Treg regulate B cell responses, and CD183+CD25 ${ }^{\text {high }}$ CD278+ CD8 Treg are more powerful regulators of B cell proliferation and Immunoglobulin production than CD183+CCR7+CD45RA- CD8 Treg, and therefore, may be used as preferred markers for CD8 Treg.

Key Words: CD8 Treg, B cell proliferation, Immunoglobulin production, ICOS

\section{INTRODUCTION}

In humans, suppressor activity in peripheral blood mononuclear cells and $\mathrm{T}$ cells against differentiation of B cells to immunoglobulin producing plasma cells was described in 1970's (1,2). Following the discovery of hybridoma and development of monoclonal antibodies, Strelkauskas et al [3] reported natural suppressor activity in OKT8+ (CD8+) T cells, whereas helper activity was in OKT4+ (CD4+) T cells. Damle and Gupta $[4,5]$ reported generation of suppressor $\mathrm{T}$ cells activity in CD8+ $\mathrm{T}$ cells following activation with concanavalin A and in autologous T-T mixed lymphocyte reaction. However, the field of suppressor T cells came to a halt due to lack of identification of molecular basis of immune suppression.

In 1982, Damle and Gupta [6] were first to demonstrate that concanavalin A activated CD4+ T cells possess regulatory activity (CD4 Treg), suppressing T cells responses in autologous and allogeneic mixed lymphocyte reaction and response of $\mathrm{T}$ cells to pokeweed mitogen. In 1995, Sakaguchi et al (7) further defined regulatory activity of CD4+ T cells in a subset that expressed CD25. However, CD25 was also expressed on non-regulatory CD4+ T cells, especially following activation. In 2003, they reported that FoxP3 transcription factor was responsible for mediating CD4 Treg activity [8]. Since then FoxP3+CD4 Treg have been extensively studies in both mice and human and various diseases and disease models [9, 11].

In past few years there has been renewed interest in CD8+ $\mathrm{T}$ regulatory cells. Experiments in mice models of human diseases have provided strong evidence of the presence of CD8+ $\mathrm{T}$ regulatory cells (CD8 Treg) and their role in the control of several autoimmune disease models [12-16]. Recently, human CD8+ T cells with suppressor activity have also been implicated in several autoimmune diseases, $[17,18]$. Shi and associates [19] have reported that human CD8+CXCR3+ (CD183+) T cells have same function as murine CD8+CD122+ Treg, and suppression of CD8+ T cell function is mediated by IL-10. These cells are CD62L+CD45RA-, similar to central memory CD8+ T cells. We have further characterized FoxP3+ CD8Treg as CD8+CD183+CD25 ${ }^{\text {high }}$ CD278+(ICOS+). In humans, CD8+ T cell 
(CD8+CD183+CD62L/CCR7+CD45RA-) regulatory activity has been demonstrated against autologous and allogeneic T cell responses; however, there are no reports of CD8 Treg activity against B cell responses.

Therefore, in this study we have examined the effect of two types CD8 Treg (CD8+CD183+CCR7+CD45RA and CD8+CD183+CD25 ${ }^{\text {high }} \mathrm{CD} 278+$, the later based upon FoxP3 expression), on B cell proliferation and Immunoglobulin production.

\section{MATERIALS AND METHODS}

\section{Subjects}

Peripheral blood was obtained from young healthy blood donors (age 20-50 years) obtained at ITRC, University of California, Irvine. The Institutional Review Board (Human) of the University of California, Irvine approved this study.

Antibodies and reagents-REDO

The anti-human antibodies and isotype controls that were used included: directly conjugated CD25 FITC, Foxp3 Alexa647, CD183 PE (CXCR3), CCR7 FITC, CD45 RA APC, CD45RA PE, LAP-1 PerCP-Cy5.5, CD278 (ICOS) PerCP-Cy5.5, anti-CTLA-4 APC with appropriate Isotype control antibodies and Foxp3 Buffer Set were purchased from (BD Biosciences San Jose, CA, USA). CD19 PerCP, CD8 PerCP cy 5.5, CD183 PE, CCR7 FITC, CD45RA APC, CD25 FITC and CD278 (ICOS) Alexa, and anti-CD40/TNFRSF5 were purchased from BD Pharmingen, San Jose, California. EasySep Human CD19 Positive and Human CD8 Positive Selection Kits were purchased from Stem Cell Technologies (Vancouver, British Columbia, Canada). Dynabeads, Human T-Activator CD3/CD28 was purchased from Life technologies (Grand Island, NY, USA). CpG (ODN 2006-G5) was purchased from InvivoGen (San Diego, California).

CD8+ T cells enrichment from PBMC and sorting of CD8 Treg

CD8 T cells were purified from PBMC with magnetic beads using EasySepTM Human CD8 Positive Selection Kit II according to manufacturer's protocol. The purity of CD8+ T cells was more than 94\%. Enriched CD8 cells were activated with $15 \mu \mathrm{l} / \mathrm{ml}$ of human T-Activator CD3/CD28 in RPMI medium for 48 hrs. Cells were washed and stained with monoclonal antibodies defining two different types of CD8 Treg, CD8 PerCP cy 5.5, CD183 PE, CCR7 FITC and CD45RA APC and CD8 PerCP cy 5.5, CD183 PE, CD25FITC and CD278 (ICOS) Alexa Fluor 647 for 20min. Cells were washed and sorted for CD8+/CD183+/CD25 ${ }^{\mathrm{High}}+/ \mathrm{CD} 278+$ and for CD8+/CD183+/CCR7+/CD45RA- by BD FACS Aria II Cell Sorter (Becton Dickinson, San Jose, California).

\section{Labeling of B cells with CFSE}

B cells $\left(10^{7}\right.$ cells $\left./ \mathrm{ml}\right)$ were incubated at $37^{\circ} \mathrm{C}$ for 15 min with $5 \mu$ of $500 \mu \mathrm{M}$ CFSE diluted in PBS. In order to stop the reaction, $100 \mu \mathrm{l}$ of fetal calf serum (FCS) was added to per $\mathrm{ml}$ of cells. Cells were washed twice in RPMI-FCS and resuspended in AIM-V medium.

\section{B cell proliferation}

CFSE-labeled B cells $\left(1 \times 10^{6}\right.$ cells $\left./ \mathrm{ml}\right)$ were cultured alone or cultured at various ratios with sorted CD8 Treg and activated with $2 \mathrm{ug} / \mathrm{ml}$ of anti-human CD40/TNFRSF5 antibody and $2.5 \mathrm{ug} / \mathrm{ml}$ of CpG in AIM-V medium and incubated at $37^{\circ} \mathrm{C}$ for 5 days. CFSE labeled B cells were stained with anti CD19 PerCP antibody and isotype control. 10,000 cells were acquired (FACSCalibur, Becton Dickenson, San Jose, CA), CD19+ B cells were gated and analyzed by Flow Jo software.

for 14 days (for immunoglobulin production) in 96-well round-bottom plates by ELISA assay.

\section{Immunoglobulin Production}

Purified B cells $\left(1 \times 10^{6}\right.$ cells $\left./ \mathrm{ml}\right)$ alone or with CD8 Treg at various ratios were activated with $2 \mathrm{ug} / \mathrm{ml}$ of anti-human CD40/TNFRSF5 antibody and $2.5 \mathrm{ug} / \mathrm{ml}$ of $\mathrm{CpG}$ in AIM-V medium and cultuted at $37^{\circ} \mathrm{C}$ for 14 days. Supernatant were collected and stored at $-20 \mathrm{deg} \mathrm{C}$ until assayed for detection of Immunoglobulins 
by ELISA. Immunoglobulin levels of $\operatorname{IgA}$, IgG, IgM were determined using appropriate human ELISA kits (eBiosciences/Thermo Fisher, Waltham, MA) per manufacturer's protocol.

Statistical analysis was performed by paired student t test using Prism 7 software. A value of $<0.05$ is considered significant.

\section{RESULTS}

CD183+CCR7+CD45RA- CD8+Treg inhibit B cell proliferation

Purified B cells were first labeled with CFSE and then co-cultured without or with sorted CD183+CCR7+CD45RA- CD8+Treg in B: CD8Treg ratio of 1:1, 1:1/2 and 1:1/4 and activated with antiCD40 and CpG for 5 days and proliferation was assayed for CFSE dilution. A representative flow cytometry histogram is shown in Figure 1A and cumulative data from 6 different individuals are shown in Figure 1B. Data are expressed as mean +-sem. A significant inhibitory effect was observed only at B: CD8Treg ratio of $1: 1$.

CD183+CCR7+CD45RA- CD8+Treg inhibit Immunoglobulin production

Purified B cells were cultured alone or with CD8 Treg at and activated with 2ug/ml of anti-human CD40 antibody and $2.5 \mathrm{ug} / \mathrm{ml}$ of $\mathrm{CpG}$ and incubated at $37 \mathrm{degC}$ for 14 days. Culture supernatants were collected and IgM, IgG, and IgA measured by ELISA kit against known standards and according manufacturer's protocol. Figure 2 show data from 6 normal controls at B:CD8 Treg ratio od 1:1. CD8 Treg significantly inhibited $\operatorname{IgM}(<0.005)$ and $\operatorname{IgG}(\mathrm{P}<0.039)$ production; however, inhibition of IgA production was not significant $(\mathrm{P}>0.078)$. No significant effect was observed on 1:1/2 and 1:1/4 ratios (data not shown).

Further characterization of CD8 Treg

FoxP3 is a transcription factor responsible for regulatory activity. Since a number of molecules have been described to express on CD8 Treg (20-23), we used several of described markers on FoxP3+ and FoxP3CD8+ $\mathrm{T}$ cells to further characterize CD8 Treg. Anti-CD3/CD28 activated purified CD8+ T cells were stained with following monoclonal antibodies and isotype controls: anti-CD8-PerCP-Cy5.5, anti-CD183BV420, anti-CD25-PE-CF595, (all from BD Bioscience, San Diego, CA), anti-ICOS-APC, anti-CTLA-4APC (from Biolegend, San Diego, CA). Cells were fixated and permeabilized using the Human FoxP3 Buffer Set from BD Pharmingen ${ }^{\mathrm{TM}}$ (San Diego, CA), according to manufacturer's instructions. After wash, the cells were stained with anti-FoxP3-PE and anti-LAP-1-PerCP-Cy5.5 for 30 minutes at room temperature. Cells were gated for FoxP3 and then examined for the expression of other markers on FoxP3+ and FoxP3CD8+ T cells. Data in Figure 3A (\% of positive cells) and Figure 3B (mean fluorescence intensity, MFI) show that FoxP3+ CD8+ T cells expressed significantly higher levels of CD25, CD278 (ICOS), CTLA-4, CD183, and LAP-1 (\%) as compared to FoxP3- CD8 T cells. Therefore, we examined regulatory activity of sorted CD183+CD25 ${ }^{\text {high }} \mathrm{CD} 278+\mathrm{CD} 8+$ Treg on B cell proliferation and immunoglobulin production.

CD2 $5^{\text {high }}$ CD278+CD183+CD8+ Treg inhibit B cell proliferation

Purified B cells were first labeled with CFSE and then co-cultured without or with sorted CD25 ${ }^{\text {high }}$ CD278+CD183+CD8+ Treg in B: CD8Treg ratio of 1:1, 1:1/2 and 1:1/4 and activated with 2ug/ml of anti-CD40 and $2.5 \mathrm{ug} / \mathrm{ml}$ of $\mathrm{CpG}$ and cultured for 5 days, and proliferation was determined by CFSE dilution assay. A representative flow cytometry histogram is shown in Figure 4A and cumulative data from 6 different individuals are shown in Figure4B. CD8 Treg, in a concentration-dependent manner inhibited B cell proliferation at B:CD 8Treg ratio of 1:1 $(\mathrm{P}<0.0008), 1: 1 / 2(\mathrm{P}<0.008)$, and 1:1/4 $(\mathrm{P}>0.80)$.

CD25 ${ }^{\text {high }}$ CD278+CD183+CD8+ Treg Inhibit Immunoglobulin Production

Purified B cells were cultured alone or with CD25 ${ }^{\text {high }}$ CD278+CD183+CD8+ Treg at B: CD8 Treg ratios of $1: 1,1: 1 / 2$, and $1: 1 / 4$, and activated with $2 \mathrm{ug} / \mathrm{ml}$ of anti-human CD40 antibody and $2.5 \mathrm{ug} / \mathrm{ml}$ of CpG and incubated at $37 \mathrm{degC}$ for 14 days. Culture supernatants were collected and IgM, IgG, and IgA was measured by ELISA kit against known standards and according manufacturer's protocol. Figure 5 show data from 6 
normal controls. CD8 Treg inhibited significantly production of all immunoglobulin isotypes at all ratios, $\operatorname{IgM}(<0.0005)$, $\operatorname{IgG}(\mathrm{P}<0.0039)$ and $\operatorname{IgA}(\mathrm{P}<0.0078)$.

\section{DISCUSSION}

Prior to the discovery of hybridoma technology to generate monoclonal antibodies, suppressor $\mathrm{T}$ cell activity in humans was first shown by Waldmann et al (1) and Siegal et al (2). The activity of suppressor T cells was increased in patients with primary immunodeficiency, and appeared to play a role in decreased immunoglobulin production by B cells. Shou et al (24) and Gupta et al (4) reported generation of suppressor T cells activity following activation with concanavalin $\mathrm{A}$, which was altered in patients with primary immunodeficiencies (25). Schwartz et al (26) demonstrated that concanavalin A (Con A)-activated PBMC suppressed differentiation of B cells to immunoglobulin synthesizing and secreting plasma cells. We showed that Con A-activated purified $\mathrm{T}$ cells suppressed immunoglobulin production by B cells and Con A activation of $\mathrm{T}$ cells was associated with increase in $\mathrm{T} \gamma$ cells that were considered suppressor $\mathrm{T}$ cells (4). Following availability of monoclonal antibodies to define T cell subsets, Strelkauskas et al (3) reported natural suppressor activity in OKT8+ (CD8+) T cells, whereas helper activity was in OKT4+ (CD4+) T cells. Damle and Gupta (6), and Reinherz et al (27) reported that Con-A induced suppressor activity of $\mathrm{T}$ cells was in CD8+ T cells. Now more than 3 decades later interest in CD8 Treg cells has revived. In a number of experimental models and human autoimmune diseases, and cancer, its role in the regulation of immune response has been established. Shi et al [19] reported that human CD8+CD183+ T cells have same function as murine CD8+CD122+ Treg, and suppression of CD8+ T cell function is mediated by IL-10.

A number of studies have demonstrated that $\mathrm{CD} 8^{+}$Treg cells induce the expression of inhibitory receptor on monocytes and dendritic cells, suppress the proliferation of effector and memory $\mathrm{CD} 4^{+}$and $\mathrm{T}$ cells, and downregulate IFN- $\gamma$ production by $\mathrm{CD}^{+} \mathrm{T}$ cells $(23,28,29)$. However, regulatory effects of CD8 Treg on $\mathrm{B}$ cell functions have not been evaluated.

Investigators have used different surface molecules including LAP-1, CD39, PD-1, and CTLA-4 to define CD8 Treg to study their functions (20-23). In the present study, to further defined CD8 Treg, we utilized all these molecules and examined their expression on FoxP3 CD8+ T cells. Our data show that FoxP3+CD8+ T cells preferentially express CD25, CD278, CD183, CTLA-4, and LAP-1. LAP-1 is an intracellular molecule. Therefore, we utilized sorted CD $8+\mathrm{CD} 25^{\text {high }} \mathrm{CD} 183+\mathrm{CD} 278+$ Treg to compare their regulatory effect from CD8+CCR7+CD183+CD45RA- Treg cells.

In the present study, we have demonstrated that CD183+ CCCR7+CD45RA- CD8+ T reg significantly inhibited B cell proliferation and suppressed IgM and IgG secretion by B cells only at B; CD8 Treg ratio of 1:1; however, they did not significantly suppress IgA production. In contrast, CD2 $5{ }^{\text {high }}$ CD278+CD183+CD8+ Treg significantly inhibited B cell proliferation at B cell: CD8 Treg ratio of 1:1 and 1:1/2, and significantly suppressed all immunoglobulin isotypes, IgM, IgG, and IgA production at all B: CD8 Treg ratios. The suppression of Immunoglobulin production by B cells would be consistent with inhibition of plasmablasts by CD 8 Treg (30). Furthermore, CD8 Treg, define by both sets of markers, suppressed IgM production to a greater extent than IgG and IgA. We have reported increased CD8 Treg cells in patients with primary selective IgM deficiency (31) that may be one of the mechanisms of selective IgM deficiency. CD8 Treg have been shown to regulate $\mathrm{T}$ cell responses by the production of $\mathrm{IL}-10(19,23)$. A number of additional mechanisms have been reported for CD8 Treg mediated suppression of T cell responses. Chen et al (21) reported that CD8+LAP-1+FoxP3+ CD8 Treg suppress EAE that is dependent upon both TGF $\beta$ and IFN $\gamma$. However, we did not observed significantly increased expression of LAP-1 in FOXP3+ CD8 T cells as compared to FoxP3- CD8 T cells. Several investigators have reported cell-to cell contact is required for CD8 Treg-mediated suppression $(23,32,33)$. Cosimi et al (23) reported abrogation of CD8 Treg-mediated suppression of T cell responses by anti-CTLA-4 and TGF $\beta$ antibodies. Cai et al (33) reported CD8 Tregmediated suppression via IL-10, TGF $\beta$ and CTLA-4. The mechanism (s) of CD8 Treg-mediated suppression of $\mathrm{B}$ cell proliferation and immunoglobulin production remains to be investigated.

In summary, CD8 Treg inhibit B cell proliferation and differentiation into immunoglobulin producing cells. 
CD25 ${ }^{\text {high }} \mathrm{CD} 278+\mathrm{CD} 183+\mathrm{CD} 8+\mathrm{T}$ reg were more effective in regulating B cell responses as compared to CD183+ CCCR7+CD45RA-+ CD8+ Treg. CD8 Treg-mediated suppression of antibody production may be one of the mechanisms of its role in autoimmune diseases, and in antibody deficiency disorders.

\section{ACKNOWLEDGEMENTS}

This investigation was supported by unrestricted funds from Division of Basic and Clinical Immunology, University of California, Irvine.

\section{AUTHOR CONTRIBUTION}

HS performed majority of experiments except immunoglobulin production assay. SA performed immunoglobulin assay and analyzed the data. SG conceived the idea, designed the experiments, supervised HS, and wrote the manuscript.

\section{CONFLICT OF INTEREST}

Authors declare no competitive financial interests in relation to the work described in this manuscript.

\section{REFERENCES}

1. Waldmann TA, Broder S, Krakauer R, MacDermott RP, Durm M, Goldman C et al. The role of suppressor cells in the pathogenesis of common variable hypogammaglobulinemia and the immunodeficiency associated with myeloma. Fed Proc. 1976; 35: 2067-2072.

2. Siegal FP, Siegal M, Good RA. Suppression of B-cell differentiation by leukocytes from hypogammaglobulinemic patients.J Clin Invest. 1976; 58:109-22.

3. Strelkauskas AJ, Schauf V, Wilson BS, Chess L, Schlossman SF. Isolation and characterization of naturally occurring subclasses of human peripheral blood T cells with regulatory functions. J Immunol. 1978; 120: $1278-82$.

4 Gupta S, Schwartz SA, Good RA. Subpopulations of human T lymphocytes. VII. Cellular basis of concanavalin A-induced $\mathrm{T}$ cell-mediated suppression of immunoglobulin production by B lymphocytes from normal humans. Cell Immunol. 1979; 44: 242-251.

5. Damle N, Gupta S. Autologous mixed lymphocyte reaction in man. V. Functionally and phenotypically distinct human T-cell subpopulations respond to non-T and activated T cells in AMLR. Scand J Immunol. 1982; 16: 59-68.

6. Damle NK, Gupta S. Heterogeneity of concanavalin A-induced suppressor T cells in man defined with monoclonal antibodies. Clin Exp Immunol. 1982; 48: 581-588.

7. Sakaguchi S, Sakaguchi N, Asano M, Itoh M, Toda M. Immunological self tolerance maintained by activated T cells expressing IL-2 receptor alpha chain (CD25) Breakdown of a single mechanism of self tolerance causes various autoimmune diseases. J. Immunol. 1995; 155: 1151-1164

8. Hori S, Nomura T, Sakaguchi S. Control of regulatory T cell development by the transcription factor FoxP3. Science 2003; 299: 1057-1061.

9. Fontenot JD, Gavin MA, Rudensky AY. FoxP3 programs the development and function of CD4+CD25+ regulatory T cells. Nat. Immunol. 2003; 4: 330-336.

10. Nakamura K, Kitani A, Fuss I, Pedersen A, Harada N, Nawata H et al. TGF-beta 1 plays an important role in the mechanisms of CD4+CD25+ regulatory cell activity in both humans and mice. J. Immunol. 2004; 172: 834-842.

11. Bennett CL, Christie J, Ramsdell F, Brunkow ME, Ferguson PJ, Whitesell L, et al. The immune dysregulation, polyendocrinopathy, enteropathy, X-linked syndrome (IPEX) is caused by mutations of FOXP3. Nat. Genet. 2001; 27: 20-21. 
12. Endharti AT, Okuno Y, Shi Z, Misawa N, Toyokuni S, Ito M, et al. CD8+CD122+ regulatory T cells (Tregs) and CD4+ Tregs cooperatively prevent and cure CD4+ cell-induced colitis. J Immunol. 2011; 186: 41-52.

13. Lee YH, Ishida Y, Rifa'i M, Shi Z, Isobe K, Suzuki H. Essential role of $\mathrm{CD} 8^{+} \mathrm{CD} 122^{+}$Treg in the recovery from experimental autoimmune encephalomyelitis. J. Immunol. 2008; 180: 825-832.

14. Ménager-Marcq I, Pomié C, Romagnoli P, van Meerwijk JP. CD8 ${ }^{+}$CD28- regulatory T lymphocytes prevent experimental inflammatory bowel disease in mice. Gastroenterology 2006; 131: 1775-1785.

15. Wildin RS, Ramsdell F, Peake J, Faravelli F, Casanova J L, Buist N, et al. X-linked neonatal diabetes mellitus, enteropathy and endocrinopathy syndrome is the human equivalent of mouse scurfy. Nat. Genet. 2001; 27: 18-20.

16. Chen M-L, Yan B-S, Kozoriz D, Weiner HL. Novel CD8+ Treg suppress EAE by TGF $\beta-$ and IFN- $\gamma-$ dependent mechanisms. Eur. J. Immunol. 2009; 39: 3423-46.

17. Brimnes J, Allez M, Dotan I, Shao L, Nakazawa A, Myer L. Defect in CD8+ regulatory T cells in the lamina propria of patients with inflammatory bowel disease. J. Immunol. 2005; 174: 5814-5822.

18. Tennakoon DK, Mehta RS, Ortega SB, Bhoj V, Racke MK, Karandikar NJ. Therapeutic induction of regulatory, cytotoxic CD8+ T cells in multiple sclerosis. J. Immunol. 2006; 176: 119-126.

19. Shi Z, Okuno Y, Rifa'I M, Endharti AT, Akane K, Isobe K-I, et al. Human CD8+CCR3+ T cells have same function as murine CD8+CD122+ Treg. Eur. J. Immunology 2009; 39: 2106-2119.

20. Deaglio S, Dwyer KM, Gao W, Friedman D, Usheva A, et al. Adenosine generation catabolized by CD39 and CD73 expressed on regulatory T cells mediate immune suppression. J. Exp. Med. 2004; 1257-1265

21. Chen M-L, Yan B-S, Kozoriz D, and Weiner HL. Novel CD8+ Treg suppress EAE by TGF $\beta$ - and IFN- $\gamma$-dependent mechanisms. Eur. J. Immunol. 2009; 39: 3423-3446.

22, Dai H, Wan N, Zhang S, Moore Y, Wan F, Dai Z. Cutting Edge: Programmed death-1 defines CD8+CD122+ T cells as regulatory versus memory T cells. J. Immunol. 2010; 124: 1130-1143.

23. Cosmi L, Liotta F, Lazzeri E, Francalanci M, Angeli R, Mazzinghi B et al. Human CD8+CD25+ thymocytes share phenotypic and functional features with CD4+CD25+ regulatory thymocytes. Blood 2003; 102: 4107-4114

24 Shou L, Schwartz SA, Good RA. Suppressor cell activity after concanavalin A treatment of lymphocytes from normal donors. J Exp Med. 1976; 143: 1100-1110.

25. Schwartz SA, Choi YS, Shou L, Good RA. Modulatory effects on immunoglobulin synthesis and secretion by lymphocytes from immunodeficient patients. J. Clin. Invest. 1977; 59: 1176-1187

26. Schwartz SA, Shou L, Good RA, Choi YS. Suppression of immunoglobulin synthesis and secretion by peripheral blood lymphocytes by from normal donors. Proc. Natl. Acad. Sci. (USA) 1977; 74: 2099-2103.

27. Reinherz EL., Kung PC, Goldstein G, Schlossman SF. A monoclonal antibody reactive with the human cytotoxic/suppressor T cell subset previously defined by a hetero antiserum termed TH2. J. Immunol. 1980; 124: 1301-1307.

28. Chang CC, Ciubotariu R, Manavalan JS, Yuan J, Colovai AI, Piazza Fet al. Tolerization of dendritic cells by TS cells: the crucial role of inhibitory receptors ILT3 and ILT4. Nat Immunol 2002;3 : 237-243;

29. Long X, Cheng Q, Liang H, Zhao J, Wang J, Wang W et al.Memory CD4+ T cells are suppressed by CD8+ regulatory T cells in vitro and in vivo. Am J Transl Res 2017; 9: 63-78

30. Gupta S and Agrawal S. In vitro effect of CD8 Treg on B cell subsets. Int. Arch. Allergy Immunol. 2020 ; 
31. Louis AG, Agrawal S, Gupta S. Analysis of subsets of B cells, Breg, CD4 Treg, and CD8 Treg in adult patients with selective IgM deficiency. Amer. J. Clin. Exp. Immunol. 2017; 5: 21-32.

32. Jarvis LB, Matyszak MK, Duggleby RC, Goodall JC, Hall FC, Gaston JS. Autoreactive human peripheral blood CD8+ T cells with a regulatory phenotype and function. Eur. J. Immunol. 2005; 35: 2896-2908.

33. Cai J, Lee J, Jankowska-Gan A, Derks R, Pool J, Mutis T, et al Minor H antigen HA-1-specific regulator and effector CD8+ T cells and HA-1 microchimerism in allograft tolerance. J. Exp. Med. 2004; 199: 1017-1023.

\section{LEGEND TO FIGURES}

Figure 1. Effect of CD8 Treg (CD183+CCR7+CD45RA-CD8+) on B cell proliferation. Purified CFSE labeled B cells were co-cultured in the presence or absence of various concentrations of CD183+CCR7+CD45RA- CD8 Treg and activated with anti-CD40 and CpG for 5 days. Cell division was measured by flow cytometry. (A) shows a representative flow cytometry histogram. (B) shows cumulative data from 6 different normal donors as mean \pm sem. Inhibition was observed only at 1:1 B:CD8 Treg ratio.

Figure 2. Effect of CD8 Treg (CD183+CCR7+CD45RA-CD8+) on immunoglobulin production. Purified B cells were co-cultured in the presence or absence of CD183+CCR7+CD45RA- CD8 Treg at 1:1 ratio and activated with anti-CD40 and CpG for 14 days. Supernatants were collected and immunoglobulins were measured by ELISA assay. Data are expressed for 6 subjects as mean \pm sem. CD8 Treg inhibited significantly IgM $(\mathrm{P}<0.005)$ and $\operatorname{IgG}(\mathrm{P}<0.039)$ production. No significant effect was observed on IgA production $(\mathrm{P}>0.7)$.

Figure 3. Further characterization of CD8 Treg. Activated CD8+ T cells were stained with various monoclonal antibodies and isotype controls. FoxP3+ cells were gated and examined for the expression of different antigens. (A) expression of molecules on \% of CD8+ T cells, and (B) mean flourescence intensity (MFI) of the different molecules. Data are shown for 5 different subjects and expressed as mean \pm sem. A significant $\left(^{*}\right)$ increased $(<\mathrm{P} .005)$ expression of CD25, CD183, CD278, CTLA-4, and LAP-1was observed on FoxP3+ CD8+ T cells as compared to FoxP3- cells.

Figure 4. Effect of CD8 Treg $\left(C D 183+C D 25^{\text {high }} C D 278+C D 8+\right)$ on $B$ cell proliferation.Purified CFSE labeled B cells were co-cultured in the presence or absence of various concentrations of CD183+CD25 ${ }^{\text {high }} \mathrm{CD} 278+\mathrm{CD} 8$ Treg and activated with anti-CD40 and CpG for 5 days. Cell division was measured by flow cytometry. (A) shows a representative flow cytometry histogram.(B) shows cumulative data from 6 different normal donors as mean \pm sem. In a concentration-dependent manner CD8 Treg inhibited B cell proliferation.

Figure 5. Effect of CD8 Treg (CD183+CD25 $\left.{ }^{\text {high }} C D 278+C D 8+\right)$ on immunoglobulin production. Purified B cells were co-cultured in the presence or absence of CD183+CD25 ${ }^{\text {high }}$ CD278+ CD8 Treg at various ratios and activated with anti-CD40 and CpG for 14 days. Supernatants were collected and immunoglobulins were measured by ELISA assay. Data are shown from 5 separate subjects (mean \pm sem). CD 8 Treg markedly inhibited IgM, IgG, and IgA production at all B cell:CD8 Treg ratios.

\section{Hosted file}

image1.emf available at https://authorea.com/users/320544/articles/450067-cd8-treg-cellsinhibit-b-cell-proliferation-and-immunoglobulin-production

\section{Hosted file}

image2.emf available at https://authorea.com/users/320544/articles/450067-cd8-treg-cellsinhibit-b-cell-proliferation-and-immunoglobulin-production

\section{Hosted file}


image3.emf available at https://authorea.com/users/320544/articles/450067-cd8-treg-cellsinhibit-b-cell-proliferation-and-immunoglobulin-production

\section{Hosted file}

image4.emf available at https://authorea.com/users/320544/articles/450067-cd8-treg-cellsinhibit-b-cell-proliferation-and-immunoglobulin-production

\section{Hosted file}

image5.emf available at https://authorea.com/users/320544/articles/450067-cd8-treg-cellsinhibit-b-cell-proliferation-and-immunoglobulin-production

\section{Hosted file}

image6.emf available at https://authorea.com/users/320544/articles/450067-cd8-treg-cellsinhibit-b-cell-proliferation-and-immunoglobulin-production

\section{Hosted file}

image7.emf available at https://authorea.com/users/320544/articles/450067-cd8-treg-cellsinhibit-b-cell-proliferation-and-immunoglobulin-production

\section{Hosted file}

image8.emf available at https://authorea.com/users/320544/articles/450067-cd8-treg-cellsinhibit-b-cell-proliferation-and-immunoglobulin-production 